\title{
Comparison of single versus double intra uterine insemination
}

\author{
B. Pathak* \\ Department of Obstetrics and Gynecology, Command Hospital Air Force, Bangalore, Karnataka, India
}

Received: 24 October 2017

Accepted: 28 October 2017

\section{*Correspondence:}

Dr. B. Pathak,

E-mail: bpathak_go@yahoo.co.in

Copyright: $\odot$ the author(s), publisher and licensee Medip Academy. This is an open-access article distributed under the terms of the Creative Commons Attribution Non-Commercial License, which permits unrestricted non-commercial use, distribution, and reproduction in any medium, provided the original work is properly cited.

\section{ABSTRACT}

Background: Intrauterine insemination (IUI) is the best studied and most widely practised artificial insemination technique. The aim and objective of this study was to compare the efficacy of single and double intrauterine insemination.

Methods: This prospective randomized study was carried out in 197 infertile couples. Controlled ovarian hyperstimulation was carried out by standard ovulation induction protocols. Single intrauterine insemination was applied 36 hours after human chorionic gonadotropin (hCG) injection to 101 patients in the first group. Double intrauterine inseminations were carried out in 96 patients to whom the first insemination was done after 24 hours and the repeat insemination was done after 48 hours of hCG injection.

Results: In the single IUI group 14 patients conceived with pregnancy rate of $13.86 \%$. In the double IUI group 18 patients conceived with pregnancy rate of $18.75 \%$. There was no statistically significant difference between the two groups as the $\mathrm{p}$ is more than 0.05 .

Conclusions: As double intrauterine insemination does not give better result and it involves more cost and stress to the couple, single intrauterine insemination should be preferable. However, further larger sample size studies are required for confirmation if any significant difference can be achieved between the two approaches.

Keywords: Double, Insemination, Intrauterine, Pregnancy rate, Single

\section{INTRODUCTION}

Intrauterine insemination (IUI) is the best studied and most widely practised artificial insemination technique. It involves placement of approximately $0.5 \mathrm{ml}$ of washed, capacitated, processed and concentrated sperm into uterine cavity via transcervical catheter to enhance the chances of fertilization. ${ }^{1,2}$

Currently, IUI is most commonly used for treatment of cervical factor infertility, abnormal male factor and unexplained infertility. When spontaneous pregnancy rates are compared with timed postcoital pregnancy rates, IUI is found to significantly increase the pregnancy rates in unexplained and moderately severe male infertility cases. ${ }^{3}$ Because of the relative simplicity of the procedure and cost effectiveness compared to in vitro fertilization (IVF) technology, it is gaining popularity in those areas where results are also comparable. Cumulative pregnancy rate following three sequential cycles of IUI was found to be similar to that with IVF. As per meta-analysis, single cycle IUI application, together with ovarian stimulation, resulted in pregnancy in $16.4 \%$ of cases. ${ }^{4,5}$ Therefore, IUI could be a satisfactory treatment modality in properly selected cases to have good results at a low cost.

\section{METHODS}

This was a prospective randomized study carried out in 197 infertile patients. The patients were randomly distributed in two groups. Couples willing for pregnancy 
but did not conceive even after one year of regular sexual intercourse, having a valid indication of IUI, sperm count more than 10 million $/ \mathrm{ml}$, female age less than 35 years and day 3 FSH less than $10 \mathrm{mIU} / \mathrm{ml}$ were included in the study. All patients were carefully evaluated after taking consent for becoming part of the study. All female partners have undergone routine investigations including blood counts including ESR, blood sugar blood grouping, STS, HBsAg, HIV, X-ray chest, USG abdomen and pelvis, HSG/diagnostic hystero-laparoscopy, thyroid profile, prolactin, AMH, FSH and LH on day 02/03, before they entered into the study. All male partners have undergone semen analysis before they were included. Patients with a minimum sperm count of 10 million $/ \mathrm{cm}^{3}$, motility criteria of $\geq 40 \%$, i.e. sum of progressive motility (3+) and (4+), and a normal sperm ratio according to Kruger's strict criteria of $\geq 10 \%$ were included in the IUI program.

Patients included in the study were divided into two groups. In the first group of 101 patients, we applied single IUI 36 hours after 10,000 IU of human chorionic gonadotropin (hCG) administration, following ovulation induction. In the second group of 96 patients, we applied two IUIs at 24 and 48 hours after 10,000 IU hCG injection, following ovulation induction.

For ovulation induction, patients with no previous ovulation induction were give Clomiphene citrate. Patients who had previous history of Clomiphene citrate use or Clomiphene citrate without successful pregnancy, Clomiphene citrate and gonadotropins were used. The ratio of patients induced with each method was similar in the two groups. During ovulation induction with clomiphene citrate, we started the drug on the $2^{\text {nd }}$ or $3^{\text {rd }}$ day of the menstrual cycle with a dose of $100 \mathrm{mg}$ per day for 5 days. In patients previously treated with clomiphene citrate, recombinant FSH 75 or 150 IU on day 8,9 and 10 was used after clomiphene citrate $100 \mathrm{mg}$ daily from day 2 / day 3. Recombinant FSH / HMG was continued by increasing the dose until an 18-mm follicle was detected. All patients were subjected to follicular monitoring from day 8 or day 9 and followed up till follicular size reaches 18-20 mm size.

Ovulation was triggered by 10,000 IU of hCG. The semen preparation was done by swim-up technique. In the single IUI group, IUI was carried out 36 hours after hCG administration; whereas in the second group, two IUI were carried out at 24 and 48 hours after hCG administration. IUI was performed by an IUI catheter in lithotomy position after the vagina and the cervix had been washed with isotonic solution. After the procedure, the patients rested on the treatment table for up to 30-40 minutes. All patients were called after 03 weeks after IUI or $2^{\text {nd }} / 3^{\text {rd }}$ day of next menstruation whichever was earlier. Patients who missed period were tested for urine pregnancy test. These patients were followed up by transvaginal sonography for confirmation of fetal cardiac activity. The statistical significance of the results was evaluated using the SPSS version 11.0 (SPSS Inc., Chicago, IL, USA) for Windows software. The data were defined by mean and standard deviation. Comparisons of data were carried out using Chi-squared tests and Fisher's exact test. Statistical significance was accepted at $p<0.05$.

\section{RESULTS}

Total 197 patients were included in the study, 101 $(51.27 \%)$ in single IUI and $96(48.73 \%)$ in double IUI group. In single IUI group, 14 out of 101 patients conceived (success rate $13.86 \%$ ). In double IUI group, out of 96 patients, 18 patients conceived (success rate $18.75 \%$ ) (Table 2). There was no statistically significant difference between the two groups according to age (both male and female partners), the duration of infertility, ovulation induction agents or pre-wash and post-wash sperm parameters (sperm count and motility) and prewash grade IV motility ( $>>0.05)$. The ages, durations of infertility, ovulation induction agents, pre-wash and postwash sperm parameters in both the groups are shown in Table 1.

Table 1: Comparison of study groups and various parameters.

\begin{tabular}{|llll|}
\hline & $\begin{array}{l}\text { Single IUI } \\
\text { group } \\
(\mathrm{N}=101)\end{array}$ & $\begin{array}{l}\text { Double IUI } \\
\text { group } \\
(\mathrm{N}=96)\end{array}$ & $\begin{array}{l}\text { P } \\
\text { value }\end{array}$ \\
\hline $\begin{array}{l}\text { Age of } \\
\text { female } \\
\text { (years) }\end{array}$ & $27.21 \pm 3.943$ & $27.64 \pm 4.268$ & NS \\
\hline $\begin{array}{l}\text { Age of male } \\
\text { (years) }\end{array}$ & $32.27 \pm 4.310$ & $32.08 \pm 4.252$ & NS \\
\hline $\begin{array}{l}\text { Duration of } \\
\text { infertility } \\
\text { (years) }\end{array}$ & $5.01 \pm 2.274$ & $5.18 \pm 2.484$ & NS \\
\hline $\begin{array}{l}\text { Pre-wash } \\
\text { sperm count } \\
\text { (million/ml) }\end{array}$ & $83.96 \pm 24.221$ & $79.58 \pm 21.24$ & NS \\
\hline $\begin{array}{l}\text { FSH on day } \\
3 \text { (mIU/ml) }\end{array}$ & $6.20 \pm 2.364$ & $6.24 \pm 2.186$ & NS \\
\hline $\begin{array}{l}\text { LH (day 3) } \\
\text { (mIU/ml) }\end{array}$ & $4.76 \pm 2.162$ & $4.82 \pm 2.288$ & NS \\
\hline $\begin{array}{l}\text { E2 (day 3) } \\
\text { (pg/ml) }\end{array}$ & $40.04 \pm 15.464$ & $42.04 \pm 15.872$ & NS \\
\hline \begin{tabular}{l} 
NS = Not significant $(\mathrm{p}>0.05)$ \\
\hline
\end{tabular} & & \\
\hline
\end{tabular}

Age of the male partners varied between 22 to 43 years. When pregnancy is compared in single and double IUI group, it has been found that pregnancy rate is higher in double IUI in all the age groups, $13.95 \%$ versus $19.05 \%$ in $22-30$ years, $15.15 \%$ versus $20.00 \%$ in $31-35$ years, and $13.63 \%$ versus $20.00 \%$ in $36-40$ years age group (Table 3). However, none of the differences is statistically significant $(\mathrm{p}>0.05)$. Female age in the study varied from 20 to 30 years. Pregnancy rate has been found to be more in double IUI in age group of 20 to 25 years $(15.00 \%$ versus $25.00 \%)$. Pregnancy rate is more in 
single IUI in age group 26 to 30 years $(19.04 \%$ versus $16.32 \%)$. However, none of the differences is statistically significant.
Double IUI has yielded pregnancy rate of $13.33 \%$ in age group of 31 to 36 years in comparison to no pregnancy in single IUI group (Table 4).

Table 2: Outcomes of intrauterine insemination in patients from both groups.

\begin{tabular}{|ll|ll|} 
& Single IUI group $(\mathbf{N}=101)$ & Double IUI group $(\mathbf{N}=96)$ & P Value \\
\hline Pregnancy (+) & 14 & 18 & \\
\hline Pregnancy (-) & 87 & 78 & NS \\
\hline Percentage of pregnancy & 13.86 & 18.75 & \\
\hline
\end{tabular}

Table 3: Male age specific pregnancy rate in single and double IUI.

\begin{tabular}{|lllllll|}
\hline $\begin{array}{l}\text { Age Groups } \\
\text { (years) }\end{array}$ & Number of patients & Number of Pregnancy & \% of pregnancy \\
\hline $22-30$ & Single IUI & Double IUI & Single IUI & Double IUI & Single IUI & Double IUI \\
\hline $31-35$ & 43 & 42 & 06 & 08 & 13.95 & 19.05 \\
\hline $36-40$ & 33 & 35 & 05 & 07 & 15.15 & 20.00 \\
\hline $41-43$ & 22 & 15 & 03 & 03 & 13.63 & 20.00 \\
\hline
\end{tabular}

Table 4: Female age specific pregnancy rate in single and double IUI.

\begin{tabular}{|lllllll|}
\hline $\begin{array}{l}\text { Age Groups } \\
\text { (years) }\end{array}$ & Number of patients & Number of Pregnancy & \% of pregnancy \\
\hline $20-25$ & Single IUI & Double IUI & Single IUI & Double IUI & Single IUI & Double IUI \\
\hline $26-30$ & 40 & 32 & 06 & 08 & 15.00 & 25.00 \\
\hline $31-35$ & 42 & 49 & 08 & 08 & 19.04 & 16.32 \\
\hline
\end{tabular}

Table 5: Duration of infertility and pregnancy rate in single and double IUI.

\begin{tabular}{|lllllll|}
\hline $\begin{array}{l}\text { Duration of infertility } \\
\text { (years) }\end{array}$ & \multicolumn{2}{l}{$\begin{array}{l}\text { Number of patients } \\
\text { Single IUI }\end{array}$} & Double IUI & Sumber of pregnancy & \multicolumn{2}{l|}{ \% of pregnancy } \\
\hline up to 05 & 68 & 59 & 10 & Double IUI & Single IUI & Double IUI \\
\hline 06-10 & 31 & 35 & 04 & 12 & 16.17 & 20.33 \\
\hline More than 10 & 02 & 02 & 00 & 06 & 12.90 & 17.14 \\
\hline
\end{tabular}

Table 6: Ovulation induction drugs and pregnancy rate in single and double IUI.

\begin{tabular}{|lllllll|}
\hline $\begin{array}{l}\text { Ovulation induction } \\
\text { drugs }\end{array}$ & Number of patients & \multicolumn{2}{l|}{ Number of pregnancy } & \multicolumn{2}{c|}{ \% of pregnancy } \\
\cline { 2 - 6 } & Single IUI & Double IUI & Single IUI & Double IUI & Single IUI & Double IUI \\
\hline C C and FSH & 63 & 54 & 05 & 06 & 07.93 & 11.11 \\
\hline C C and hMG & 24 & 30 & 06 & 08 & 25.00 & 26.67 \\
\hline
\end{tabular}

In this study, 127 patients $(64.47 \%)$ were having infertility of up to 5 years and 66 patients $(33.50 \%)$ had infertility of 6 to 10 years duration. Only 4 patients $(02.03 \%)$ had infertility of more than 10 years. Better pregnancy rate has been achieved in double than single IUI in both groups, i.e. $16.17 \%$ versus $20.33 \%$ in infertility up to 5 years and $12.90 \%$ vs $17.14 \%$ in infertility for 6 to 10 years group (Table 5).

However, difference is not statistically significant. No pregnancy could be achieved in those 02 women in each group with infertility of more than 10 years.
Clomiphene citrate was used as ovulation induction drug in 117 patients $(59.39 \%)$ whereas clomiphene citrate and FSH in 54 patients $(27.41 \%)$ and clomiphene citrate and hMG were used in 26 patients (13.20\%). Pregnancy rate with clomiphene citrate group has been found to be better in double IUI than single IUI group $(11.11 \%$ versus $07.93 \%$ ). Double IUI has been found to be giving better results than single IUI in both clomiphene citrate and FSH $(26.67 \%$ vs $25.00 \%)$ and clomiphene citrate and hMG (33.33\% vs $21.42 \%)$ group (Table 6). However, none of the difference is statistically significant. Clomiphene citrate alone has been found to give poorer 
result than other two groups, which are statistically significant.

In this study, 19 cases $(09.65 \%)$ had pre-wash sperm count less than or equal to 50 million / $\mathrm{ml}$ and 178 cases (90.35\%) had sperm count more than 50 million / $\mathrm{ml}$. Pregnancy rate was found to be better in double IUI than single IUI in pre-wash sperm count less than or equal to 50 million / $\mathrm{ml}(18.18 \%$ versus $12.50 \%)$ which is statistically significant. Though double IUI was found to give better pregnancy rate single IUI in pre-wash sperm count more than 50 million / $\mathrm{ml}$ (18.60\% versus $14.13 \%)$, difference is statistically not significant.

\section{DISCUSSION}

There is ongoing debate on the issue of outcome of single and double IUI. Several studies have addressed this issue. Some studies show no improvement in pregnancy rates with two inseminations as compared to one well timed insemination. Other studies show significantly higher pregnancy rate when two inseminations are done. A possible explanation for this discrepancy could be that if a single insemination is not properly timed with respect to ovulation, then a two-insemination protocol provides at least one insemination with appropriate timing.

It is of utmost importance in a developing country like India to try to achieve maximum success rate in an affordable cost. Advanced assisted reproductive techniques are not affordable as first line of treatment to many couples in India. When advanced treatment is needed, neither the expertise nor the state of the art laboratory is easily available at peripheral level.

Various studies have shown that male age is an important factor in conception. Data from Society for Assisted Reproductive technology and the American Society for Reproductive Medicine, 1998 has stated age to be a significant factor affecting IUI. ${ }^{6}$ According to them, age was the only significant predictor of pregnancy rate when their data was analysed. According to study by Matheiu and colleagues two factors are of poor prognosis, i.e. duration of infertility $>3$ years $(p=0.01)$ and husband's age $(p=0.03) .^{7}$ We have not found any significant difference in fertility rate in male in age group 22 to 40 years (Table 4). However, there is significant decline in fertility after 40 years of age. Double IUI gives better pregnancy rate than single IUI in age groups up to 40 years and double IUI failed to bring better result than single IUI in males beyond 40 years of age.

Female age influences the chance to conceive and affects the outcome of IUI. The age-related decline in female fecundity in women has been well documented by NoordZaadstra V et al. in 1991, particularly in women undergoing IUI with donor sperm. ${ }^{8}$ Success rates of IVF and ICSI have been reported to decrease with advancing female age by Devroey et al and Hughes EG, indicating that the negative impact of age can be overcome only partly by ART.9,10 This decline in female fertility has been suggested to be a result of decreased oocyte quality by Navot et al. ${ }^{11}$ Reduced uterine receptivity has been suggested as a cause of this decline of fertility by Cano et al. ${ }^{12} \mathrm{We}$ have not found any significant impact of female age in pregnancy rate in the age group 20 to 30 years. There is significant decline in fertility after 30 years and significantly better pregnancy rate has been resulted by double IUI in higher age group of 31 to 35 years (Table 4).

According to study by Tomlimson MJ and colleagues, duration of infertility did not appear to affect pregnancy rate significantly unless it had continued for more than 22 months. ${ }^{13}$ The chance of conception was more than $20 \%$ in couples trying for less than 6 years. In the present study, maximum pregnancy rate has been achieved in couples with infertility up to 5 years followed by duration of infertility for 6 to 10 years. Same correlation between duration of infertility and pregnancy rate have been found when outcomes were calculated separately for single and double IUI. Double IUI produced better results in both the groups.

Randall GW and Gantt PA evaluated the effectiveness of double IUI in prospective, nonrandomized study, 595 couples utilizing clomiphene citrate - hCG (CC-hCG), CC - gonadotropin- hCG (CC-Gn-hCG), Gn-hCG, Lupron-Gn-hCG (L-Gn-hCG) or luteinizing hormone (LH) surge monitoring of natural cycles in single or double IUI in a total of 1276 cycles. ${ }^{14}$ They concluded that ovulation induction protocols using CC-Gn-hCG gives better result in double vs single IUI $(21.3 \%$ versus $13.0 \%$, p <0.03). Ragni $\mathrm{G}$ et al investigated the effectiveness of single and double IUI undergoing $\mathrm{COH}$ with clomiphene citrate and gonadotropins in total 449 cycles and concluded that clomiphene citrate and gonadotropin was the most cost-effective regimen for women undergoing $\mathrm{COH}^{7}$ Osuna $\mathrm{C}$ et al studied single versus double IUI using clomiphene citrate with or without gonadotropin as $\mathrm{COH}$ protocol and concluded that better pregnancy rate with two inseminations $(14.9 \%$ versus $11.4 \%$ ) could be achieved by using clomiphene citrate with or without gonadotropins and 5000 IU of hCG. ${ }^{15}$ In this study significantly better pregnancy rate has been achieved with the use of clomiphene citrate and gonadotropins than clomiphene citrate alone in both single and double IUI. We have not found any statistically significant difference in pregnancy rate between clomiphene citrate and FSH as compared to clomiphene citrate and $\mathrm{hMG}$ in single IUI (25\% versus $21.42 \%$ ). However, clomiphene citrate and hMG have resulted better pregnancy rate than clomiphene citrate and FSH (33.33\% versus $26.67 \%$ ) in double IUI group.

Jameel et al studied the significance of a threshold effect for the average total motile sperm count. ${ }^{16}$ With the average count of $<10 \mathrm{million} / \mathrm{ml}$, pregnancy rates are reported to be very low after IUI and when the average sperm count is above $30 \mathrm{million} / \mathrm{ml}$, a higher pregnancy 
rate is noted per IUI cycle. Though oligospermia was excluded from the present study, we have found double IUI resulted significantly better pregnancy rate than single IUI $(18.18 \%$ versus $12.50 \%)$ in patients with sperm count less than 50 million $/ \mathrm{ml}$. There are studies which conclude that double IUI is superior to single IUI overall, especially when comparing gonadotropin containing ovarian stimulation protocols. However, Cochrane database of Systematic Reviews 2003 found that in trials of IUI (when fertility drugs to induce ovulation are also used), double IUI has not resulted in more pregnancies than single IUI.

In this study, double IUI has given better pregnancy rate $(18.75 \%)$ than single IUI $(13.86 \%)$. However, the difference is not statistically significant $(\mathrm{p}>0.05)$.

\section{CONCLUSION}

Both male and female age adversely affect the pregnancy rate after IUI as duration of infertility does. Ovarian stimulation with Clomiphene citrate and gonadotropin gives better pregnancy rate than clomiphene citrate alone. Double IUI has no statistically significant advantage over single IUI. However, larger studies are required to determine if double IUI can give better results.

Funding: No funding sources

Conflict of interest: None declared

Ethical approval: The study was approved by the Institutional Ethics Committee

\section{REFERENCES}

1. Ragni G, Maggioni P, Guermandi E, Testa A, Baroni E, Colombo M, et al. Efficacy of double intrauterine insemination in controlled ovarian hyperstimulation cycles. Fertility and Sterility. 1999;72(4):619-22.

2. Silverberg KM, Johnson JV, Olive DL, Burns WN, Schenken RS. A prospective, randomized trial comparing two different intrauterine insemination regimens in controlled ovarian hyperstimulation cycles. Fertility and Sterility. 1992;579(2):357-61.

3. Cohlen BJ, Vandekerckhove P, te Velde ER, Habbema JD. Timed intercourse versus intra-uterine insemination with or without ovarian hyperstimulation for subfertility in men. Cochrane Database Syst Rev. 2000;(2):CD000360.

4. Goverde AJ, McDonnell J, Vermeiden JP, Schats R, Rutten FF, Schoemaker J. Intrauterine insemination or in-vitro fertilisation in idiopathic subfertility and male subfertility: a randomised trial and costeffectiveness analysis. Lancet. 2000;355:13-8.

5. Philips Z, Barraza-Llorens M, Posnett J. Evaluation of the relative cost-effectiveness of treatments for infertility in the UK. Hum Reprod. 2000;15:95-106.
6. Society for Assisted Reproductive technology and the American Society for Reproductive Medicine. Assisted reproductive technology in the United States: 1998 American Society for reproductive Medicine/Society for Assisted Reproductive technology registry. Fertility and Sterility. 2002;77:18-31.

7. Mathieu C, Ecochard R, Bied V, Lornage J, Czyba JC. Cumulative conception rate following intrauterine artificial insemination with husband's spermatozoa; influence of husband's age. Hum Reprod. 1995;10:1090-7.

8. van Noord-Zaadstra BM, Looman CW, Alsbach H, Habbema JD, te Velde ER, Karbaat J. Delaying childbearing: Effect of age on fecundity and outcome of pregnancy. Br Med J. 1991;302:1361-5.

9. Devroey P, Godoy H, Smitz J, Camus M, Tournaye $\mathrm{H}$, Derde MP, et al. Female age predicts embryonic implantation after ICSI: a case controlled study. Hum Reprod. 1996;11:1324-7.

10. Hughes EG. The effectiveness of ovulation induction and intrauterine insemination in the treatment of persistent infertility: a meta-analysis. Hum Reprod. 1997:12:1865-72.

11. Navot D, Goldstein N, MorJoset S, Simon A, Relou A, Birkenfeld A. Multiple pregnancies: risk factors and prognostic variables during induction of ovulation with human menopausal gonadotropins. Hum Reprod. 1995;6:1152-5.

12. Cano F, Simon C, Remohi J, Pellicer A. Effect of aging on the female reproductive system: evidence for a role of uterine senescence in the decline in female fecundity. Fertility and Sterility. 1995;64:584.

13. Tomlimson MJ, Arthur AJB, Thompson KA, Kasraie $\mathrm{JL}$, Bentick B. Prognostic indicators for intrauterine insemination (IUI): Statistical model for IUI success. Hum Reprod. 1996;11(9):1892-6.

14. Randall GW, Gantt PA. Double versus single intrauterine insemination per cycle: use in gonadotropin cycles and in diagnostic categories of ovulatory dysfunction and male factor infertility. J Reprod Med. 2008;53(3):196-202.

15. Osuna C, Matorras R, Pijoan JI, Rodriguez-Escudero FJ. One versus two inseminations per cycle in intrauterine insemination with sperm from patient's husband: a systematic review of the literature. Fertility and Sterility. 2004:82(1):17-24.

16. Jameel T. Sperm swim-up: a simple and effective technique of semen processing for IUI. J Pak Med Assoc. 2008;58(2):71.

Cite this article as: Pathak B. Comparison of single versus double intra uterine insemination. Int $\mathbf{J}$ Reprod Contracept Obstet Gynecol 2017;6:5277-5281. 